\title{
Bariatric surgery guidelines in need of revision, experts argue
}

$\mathrm{O}$ besity is one of the greatest health issues facing North Americans. On this, doctors agree. But when it comes to treating obesity, opinions are divided on just how high a body mass index (BMI) must rise before it is appropriate to consider bariatric or stomach-restricting surgeries and many doctors are now advocating for treatment at lower BMIs than previously considered.

Current guidelines to qualify for bariatric surgeries in Canada and the United States are a minimum BMI of 40 , or a BMI of 35 with one or more severe comorbidities. Dr. John Kral, a professor of surgery and medicine at the SUNY Downstate Medical Center in Brooklyn, New York, thinks it is time to revisit those numbers, which were agreed upon at a consensus conference he helped organize in 1991.

Based on those 1991 guidelines, the typical "Jane Doe of obesity surgery," as Kral describes her, is a 38-year-old woman. But Kral says it's preferable to treat patients when they are younger, before they develop a severe eating disorder, a more severe disease or get that magic BMI of 40. "People need more effective treatment when their body mass index is 30 ," he says. "There are probably people below the body mass index of 30, in the interval 25-29.9, who really need effective treatment."

In the US, the Food and Drug Administration appears receptive to the argument. In December 2010, the agency approved a request from the pharmaceutical firm Allergan to lower the minimum BMI patients had to have to be eligible for surgical insertion of a "Lap-Band device" (a restricting saline-filled ring inserted around the top part of a patient's stomach via laparoscopic surgery) to a minimum of 35 , or 30 with one or more severe comorbidities. A similar application has been made to Health Canada.

It's a promising move for less obese patients who would benefit from stomach-restricting surgery, says Dr. Chris

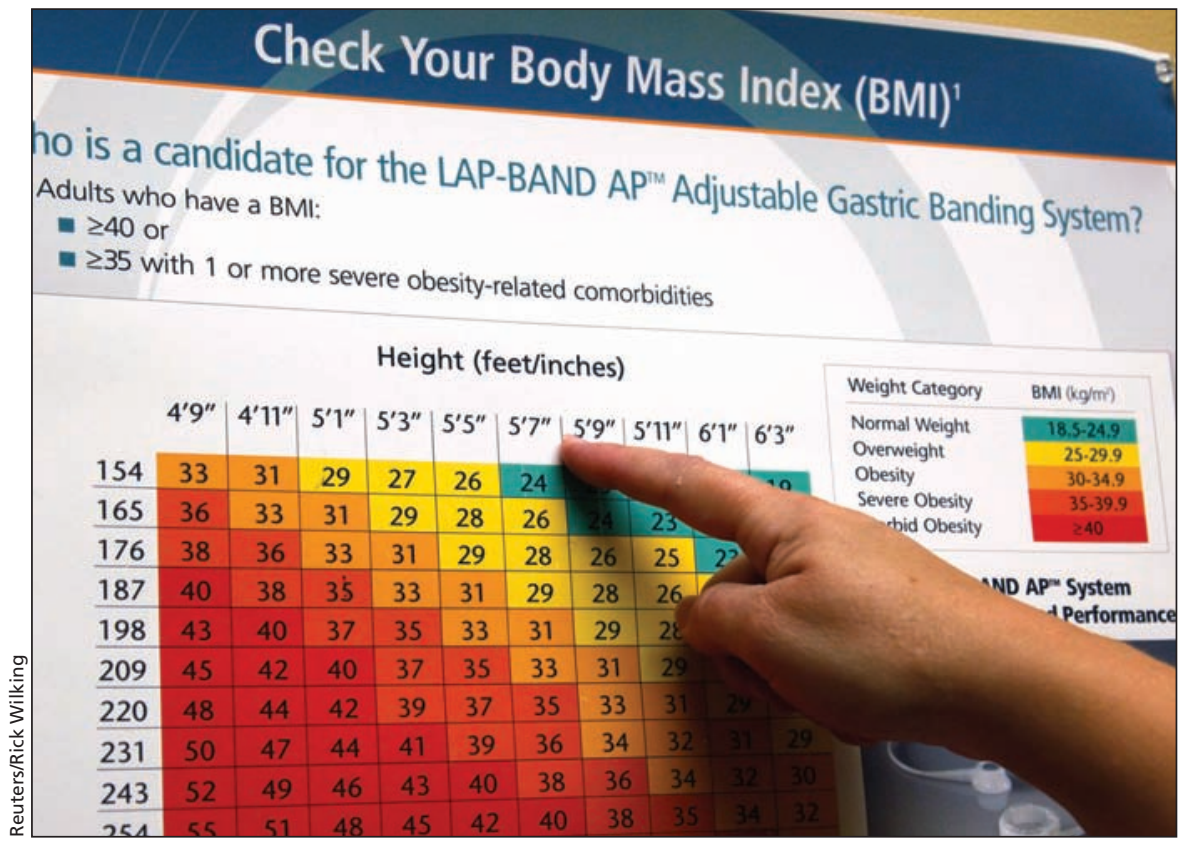

A Lap-Band surgery patient checks her body mass index on a chart in her doctor's office.

Cobourn, cofounder of the private Surgical Weight Loss Centre in Mississauga, Ontario. Cobourn, who regularly performs Lap-Band surgery, argues that patients would often qualify for surgery if they gained five pounds. "It seems discriminatory to me to say, "you must have a BMI of 35 before we would consider operating on you'," he says. "If you have the comorbidities, particularly diabetes, why should you have to gain weight to justify an operation?"

Part of the problem is the use of the BMI as a qualifying criteria. While it's a useful measure for broad-based population health studies, it doesn't translate that well in determining the health of an individual patient, says Dr. David Lau, president of Obesity Canada and professor of medicine at the University of Calgary in Alberta.

"Obesity and overweight are part of a continuum," he says. "As with all biological processes, you can't arbitrarily have a cut point, which we do [with BMI] to make it as a definition." Someone with a BMI of 30 (by definition, obese), won't necessarily have high blood pressure or diabetes, while someone with a BMI under 30 isn't always healthy, Lau adds.

Yet BMI is typically applied to individuals because physicians lack a better measurement to determine body fatness, says Lau, who believes a combined measurement of BMI and waist circumference might be more effective. "We do know that central fat distribution, the apple-type of fat distribution, is more likely to be associated with the comorbidities that accelerate cardiovascular complications, diabetes and some of the metabolic problems, such as high blood pressure, high blood fat and high cholesterol."

The unisex, uni-racial BMI system doesn't account for body frame or type, concurs Dr. Yoni Freedhoff, founder of the Ottawa Bariatric Medical Institute in Ontario. "Over half of the NFL have body mass indexes beyond 30, which means half would then qualify for LapBand surgery. We've got to deal with the patient in front of us, not just a simple number." - Emily Senger, Toronto, Ont.

CMAJ 2011. DOI:10.1503/cmaj.109-3786 